\title{
MAKER: Simple Making Activities to Expose Middle School Girls to STEM Careers
}

\section{Dr. Lunal Khuon, Drexel University}

Dr. Lunal Khuon is an Associate Clinical Professor at Drexel University in the Engineering Technology (ET) Department. He also serves as the Assistant Department Head for Graduate Studies and the Director of Research for the ET Department as well as oversees the Biomedical Engineering Technology concentration. Prior to Drexel, Dr. Khuon had previously held design and system positions at Texas Instruments, Motorola, Hughes, and IBM and faculty positions as an Assistant Professor at Villanova University and Delaware State University and an adjunct Assistant Professor at the University of Pennsylvania. His research interests are in radio frequency and analog integrated circuit design, embedded systems, biomedical electronics, and engineering education. He received his Ph.D. in Electrical Engineering and Computer Science from MIT.

\section{Dr. Yalcin Ertekin, Drexel University (Tech.) (MERGED)}

Dr. Ertekin received his BS degree in mechanical engineering from Istanbul Technical University. He received MS degree in Production Management from Istanbul University. After working for Chrysler Truck Manufacturing Company in Turkey as a project engineer, he received dual MS degrees in engineering management and mechanical engineering from Missouri University of Science and Technology (MS\&T), formerly the University of Missouri-Rolla. He worked for Toyota Motor Corporation as a quality assurance engineer for two years and lived in Toyota City, Japan. He received his Ph.D. in mechanical engineering from MS\&T in 1999 while he worked as a quality engineer for Lumbee Enterprises in St. Louis, Missouri. His first teaching position was at the architectural and manufacturing Sciences department of Western Kentucky University. He was a faculty at Trine University teaching mainly graduate courses as well as undergraduate courses in engineering technology and mechanical engineering departments. He is currently teaching in Engineering Technology Program at Drexel University. His area of expertise is in CAD/CAM, Computer Numerical Control (CNC) machining, rapid prototyping and quality control. His research interest includes sensor based condition monitoring of CNC machining, machine tool accuracy characterization and enhancement, non-invasive surgical tool design, reverse engineering and bio materials.

Mr. M. Eric Carr, Drexel University (Eng. \& Eng. Tech.)

Mr. Eric Carr is an Instructor with Drexel University's Department of Engineering Technology. A graduate of Old Dominion University's Computer Engineering Technology program and Drexel's College of Engineering, Eric enjoys finding innovative ways to use microcontrollers and other technologies to enhance Drexel's Engineering Technology course offerings. Eric is currently pursuing a Ph.D in Computer Engineering at Drexel, and is an author of several technical papers in the field of Engineering Technology Education.

\section{Prof. Brandon B. Terranova, Drexel University}

Dr. Terranova is an Assistant Teaching Professor in the College of Engineering at Drexel University. In his current role, he is the lead instructor for the freshman engineering program, and oversees activities in the Innovation Studio, a large-area academic makerspace. He has taught and developed courses in general engineering and mechanical engineering at Drexel. Prior to Drexel, he has taught and developed courses in physics and mathematics at SUNY Binghamton, University of Delaware, Missouri Online College, and St. Mark's High School. Dr. Terranova's research interests include plasmonics, optical tweezing, photonics, electromagnetism, and engineering education. He received his MS in Physics from SUNY Binghamton, and his PhD in Electrical Engineering with a concentration in Electrophysics from Drexel University for his work in 3D plasmonic nanostructures.

Dr. Simi Hoque, Drexel University

Dr. Christine Marie Fiori, Drexel University 
Dr. Christine Fiori is the Department Head of Engineering Management Studies and the Program Director of the Construction Management Program at Drexel University where she teaches courses in Project Controls, Equipment Applications and Economics, and Strategic Management. Prior to joining the faculty at Drexel University, she served as the Preston and Catharine White Fellow and Associate Director of the Myers-Lawson School of Construction at Virginia Tech. She received her BS, MS and PhD in Civil Engineering with a concentration in Geotechnical Engineering from Drexel University in 1992, 1994 and 1997 respectively. She served as a Civil Engineering officer in the United States Air Force and taught at both the United States Air Force Academy and Arizona State University. Her interest in ancient construction practices led to a National Science Foundation grant to explore the construction techniques of the Inca, specifically the Inca road throughout Peru. This research is part of a Smithsonian exhibit at the Museum of the Native American Indian through 2020. She was recognized as an Engineering News Record Top 25 Newsmakers of 2010 for her research on the Inca Road. Additionally, Dr. Fiori was featured on the Science Channel in an Episode of Strip the City pertaining to Machu Picchu. Dr. Fiori led the Construction Engineering and Management program and also facilitated the service learning programs for the Myers-Lawson School of Construction. She has led diverse groups of student teams to Vietnam, Kenya, Belize, Guatemala and Haiti to complete construction projects and community engagement programs. Currently her work is focused in Belize and Africa. She also serves as a Faculty Fellow for the Sigma Phi Epsilon fraternity, is a Bridges to Prosperity Construction Mentor, serves on the Board of Directors and as a mentor for the ACE Mentoring program of Southeastern Pennsylvania and was elected as the first Affiliate member of the Carpenters' Company of the City and County of Philadelphia.

\section{Mr. Crachad Craig Laing, Drexel University}

Crachad Laing is currently a STEM educator at Windsor Schools in, Nassau Bahamas and a co-founder of Project Limestone - a Bahamian NPO geared towards youth development. His educational background is a BS Civil Engineering from Bluefield State College and he is currently pursuing a MS Engineering Technology from Drexel University. 


\title{
MAKER: Simple Making Activities to Expose Middle School Girls to STEM Careers
}

\begin{abstract}
This paper describes a set of making activities that was utilized in Girl Makers, a week-long program that was part of a university outreach summer camp organized to inspire underrepresented middle school minority girls to choose STEM careers. With the goal to expose the students to making and makerspaces, Girls Inc. middle school students participating in Girl Makers were engaged in Arduino coding, robotics, concrete paperweight making, 3D design and printing, and CNC laser cutting and engraving activities. Each of these stand-alone activities could be completed within two and half hours including a break and, with the exception of coding, provided the students with a physical artifact to take home.

The majority of Girl Makers activities were held in a new open-access academic makerspace that normally supports the university's common first-year engineering program and senior capstone design projects. The makerspace has grown to support more informal learning programs that include STEM outreach, workshops, and entrepreneurial activities for the university community. All Girl Makers activities were organized by volunteer engineering faculty and students. Depending upon the nature of the activities, each Girl Makers workshop either made use of available fabrication equipment, reusable materials borrowed from the freshman engineering class or, low-cost readily available materials to make artifacts that the girls could take home. Discussions of science and technology concepts were incorporated formally through presentations and informally through one-to-one and small group discussions with the students. The groups of students were kept purposefully small with 8-10 girls for each session and multiple instructors and student assistants were available to provide valuable instructor-student interactions. A feedback questionnaire completed at the end of the program indicated promising student engagement and interest in the making activities.
\end{abstract}




\section{Introduction}

The purpose of this paper is to describe simple making activities that were used as part of Girl Makers, a coordinated pilot program that focuses on introducing making, makers, and a makerspace to middle school students to engage them in STEM careers. Depending upon the nature of the activities, each Girl Makers workshop either made use of available fabrication equipment normally found in an academic makerspace, reusable materials borrowed from freshman engineering classes or, low-cost readily available materials to create artifacts that the girls could take home. It is our hope that other university programs and makerspaces with limited resources that desire to engage middle school students would be able to duplicate these or similar making activities. Girl Makers itself is part of a larger Drexel STEM University summer camp for girls that provides an opportunity for volunteer Drexel University College of Engineering faculty, post-doctoral fellows, and students to interact with middle school girls from underrepresent minority groups in positive and impactful ways. It is important to emphasize that all Drexel STEM University instructors and assistants are volunteers and the instruction development and materials are donated by the instructors. The inaugural Drexel STEM University does not have similar capabilities of funded programs such Art2STEM [1] but, as discussed below, is sufficient in meeting its specific goals of exposure and engagement.

In creating Girl Makers, the intention is to expose and interest young underrepresented minority girls to STEM through making activities and give participants an opportunity to interact with and learn from STEM experts. Although training in STEM fields is important, exposure to STEM activities is the crucial first step. An article on the Huffington Post, written by Dr. Marcus Bright- Administrator at City University of New York says that, "An increased level of early exposure will help to make the requisite math courses needed for many STEM careers more relevant to students. Critical math courses are often criticized by student as being too absorbed and not relevant to the real world"'[2]. In another article from The Committee For Economic Development, Sidharth Oberoi says that, "one of the most important factors that limits the United States' ability to stay ahead of the STEM curve is the lack of introduction to these educational areas at an early age"[3]. Both these articles suggest that early exposure to STEM activities is essential to future STEM growth. Furthermore, recent surveys conducted by one of the authors, who is currently Director of STEM Initiatives, Windsor School, Nassau, Bahamas show that $60 \%$ of the middle school girls from his sample did not know what the acronym "STEM" stood for and those who did, had no interest in pursuing a STEM profession. This statistic indicates a lack of STEM exposure and emphasizes its significance as a priority in STEM programs.

The sections to follow (1) briefly describe the Drexel STEM University, (2) provide motivation for making and introduce the Innovation Studio, an academic makerspace within the College of Engineering, (3) discuss the various Girl Makers making activities, and (4) review the feedback questionnaire results from the participants and discuss future plans.

\section{Drexel STEM University}


Faculty and students from Drexel University partnered with Girls Inc. of Philadelphia to offer an inaugural unique experiential learning opportunity for middle school girls during the summer. During July 2017, the College of Engineering hosted 24 girls at the Innovation Studio and in labs and classrooms across Drexel's campus for a week-long girls only STEM summer program.

The girls were between the ages 12-14, rising 6th graders to rising 9th graders from different parts of Philadelphia. 90\% of the girls were minorities and from underrepresented groupsLatina, black, or mixed. Girls Inc. recruited the girls and they were charged at most $\$ 50$ (on a sliding scale) for the week-long full day summer program at Drexel. Each day, they learned about different STEM subjects through workshops organized and taught by 46 volunteer faculty, postdoctoral fellows, and students from across the College of Engineering. The program is intended to motivate and interest young girls from the City of Philadelphia who have not had the opportunity to interact with and learn from STEM experts on Drexel's campus. Our goal is to address the gap that begins to emerge in the middle school years among girls from underrepresented communities by creating a girls-only summer STEM program that captures their interest and provides a supportive and fun environment to learn about STEM subjects. A girls-only group is in itself a specific structure for female participants as it has been shown that girls/women feel intimidated in a majority male environment, therefore an all-female group provides a certain level of comfort, which in turn provides a conducive learning environment [4].

Drexel STEM University volunteers were given 2.5 hour periods to conduct STEM activities with the students, choosing a morning session from 9:30am-12:00pm or an afternoon session from 1:30pm-4:00pm or both. The students were divided into 3 groups consisting of 8-10 girls and each group had an adult chaperone from Girls Inc., who assisted with restroom and snack breaks during the workshops. Each group attended different activity workshops in the morning and afternoon.

\section{Making and the Innovation Studio}

Teachers have found making to be a great way to get students excited and engaged in their classrooms and have incorporated making in math and science classes [5]. Making allows students to follow their own interests and create within a STEM education framework. MakerSpaces connect the digital world to the physical world and can be a combination of computer lab, science lab, woodshop, metal shop, and art room that facilitate project-based learning [6].

The Innovation Studio is an accessible, 10,000 $\mathrm{ft}^{2}$ open-area academic makerspace open to all students, staff, and faculty in the College of Engineering. Figure 1 depicts a layout conducive for a diversity of classroom activities and sizes. The lab tables are on casters and the layout is flexible and re-configurable. The Innovation Studio is an academic makerspace in which classes are run alongside a makerspace where users are engaged in making activities [7]. This 
arrangement naturally blends formal and informal learning events, and encourages crosspollination of projects spanning a variety of skill levels (for undergraduate and graduate students), and a variety of engineering disciplines. The girls participating in Girl Makers made use of the Innovation Studio for their making activities. However, all of the Drexel STEM University students began and ended the day as well as had lunches at the Studio. This exposed every participant to the makerspace regardless of the STEM activities in which they were engaged.

The Innovation Studio houses equipment used in support of freshman engineering courses and general making activities. Some equipment is found within the "classroom" and "makerspace" areas labeled as shown in Figure 1. Letters $a$ - $d$ shown in Figure 1 depict locations for equipment ranging from 3D printers and electrical and mechanical testing equipment. The 3D printers used in the Studio are fully enclosed with HEPA filtration to reduce the amount of volatile organic compounds emitted into the space. Letters $e-g$ depict locations dedicated to CNC mills, various cutting tools, and hand tool stations. The Studio layout also indicates the locations of the wetlab, welding area, light machinery, heavy machinery, and laser cutters. The Innovation Studio has four full-time machinists on staff, a lab manager, and several undergraduate employees.

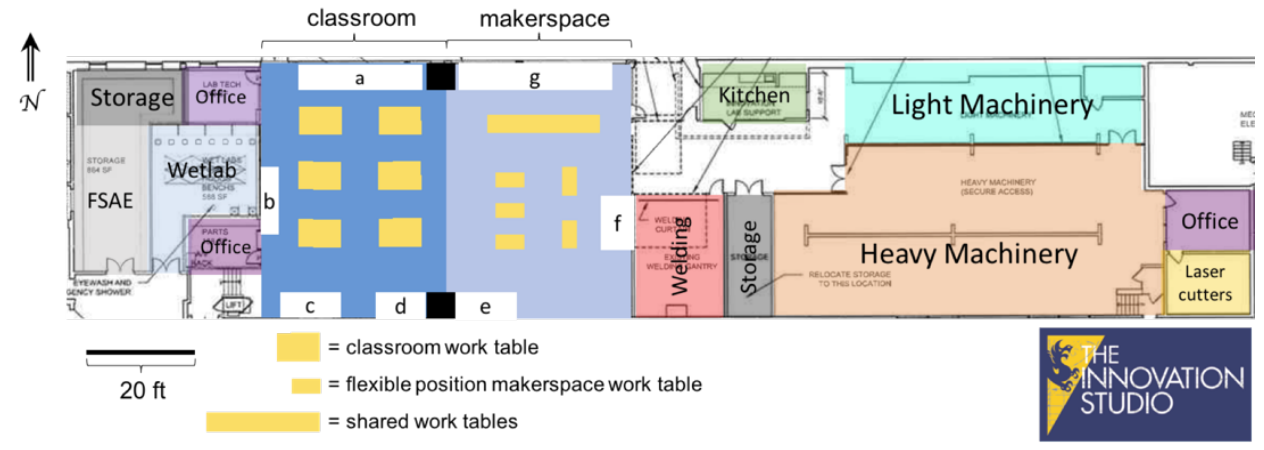

Figure 1. Innovation Studio layout.

Since its inception, the Innovation Studio has supported numerous activities including senior design/capstone projects, student recruitment, workshops, trainings, seminars and outreach events. The mission of the Innovation Studio is to provide a student-centric, project-focused collaborative shared space and equipment to the greater Drexel community in support of innovative educational, research, and entrepreneurial activities. The Innovation Studio is located on Drexel's campus in an urban environment, thus having the potential to support educational, research, and entrepreneurial activities to create an engaged and networked community of practice. Academic makerspaces such as this have been shown to improve student motivation, confidence, and retention [8].

The design-and-build nature of makerspaces complements design-focused engineering program goals, promotes an active learning culture, and empowers students to experiment with new tools and approaches. With makerspaces becoming more prevalent in primary and secondary 
education, the Innovation Studio setting will soon become a familiar learning environment to incoming students, helping to ease the transition into an engineering program.

\section{Girl Makers Activities}

In the following sections, the five activities prepared for the Girl Makers' week-long workshops are described. As mentioned previously, each activity workshop was 2.5 hours long, including a break.

\section{3D Designing and Printing a Key Ring}

In this activity, the Girl Makers are introduced to basic computer-aided design (CAD) and 3D printing. In addition to $\mathrm{CAD}$ and $3 \mathrm{D}$ printing concepts, students were introduced to TinkerCAD, a completely online CAD modeling tool which is free to use and offers a simple interface and step-by-step tutorials and exercises for those new to CAD [9]. The girls who participated in this project were first introduced to the concept of CAD and 3D printing through a short presentation with several relevant videos. Working individually, they were each provided a computer with Internet access and were guided through an introductory instructor-led exercise that followed an online step-by-step tutorial to familiarize them with the graphical user interface (GUI) for TinkerCAD and basic geometric primitives along with some associated 3D object manipulations (extrude, fillet, bevel, adjust dimensions).

After an overview of the basics, the students were then tasked with going through an online TinkerCAD tutorial "Key Ring, Letters" (see Figure 3) on their own to create a custom key ring with their name in raised lettering on it. Two of the students had prior CAD experience and finished quickly, and used their remaining time to aid other students. Once they completed their designs, STL files were created and sent to a 3D printer. At the conclusion of the activity there was time for lively conversations between the volunteer instructors and the students and several of the girls had expressed interest in engineering careers. 


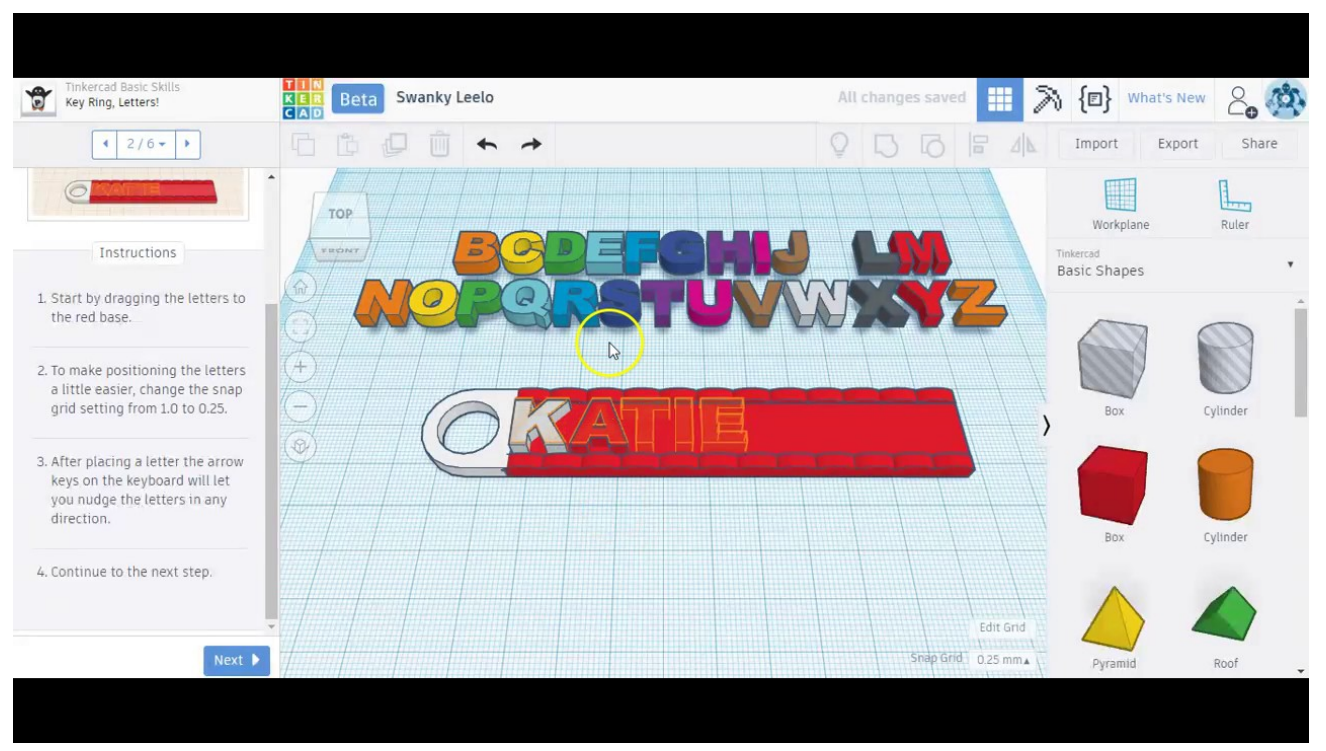

Figure 3. TinkerCAD online tutorial exercise "Key Ring, Letters!"

This activity was designed to be accessible to middle school-aged students with no CAD experience. Additionally, 3D printing was chosen because it is an exciting technology for all ages, and produces a tangible object - which serves as a token to recall their experience as well as evidence of the simplicity of going from concept to prototype with the use of 3D printing.

\section{Learning Robotics Through Making a Doodlebot}

'Making the Doodlebot' introduced the Girl Makers to robotics. As shown in Figure 4 (left), the Doodlebot consisted of a Solo cup as the robot body, four markers as the robot legs, a DC motor to provide the mechanical source for locomotion, and a battery for electrical power. Electrical tape provided the means to attach the parts of the robot together as well as to connect the battery wires to the DC motor wires. A wine bottle cork attached to the motor "amplified" the vibrations and depending on how the students attached the cork to the motor, the vibrations could propel the robot forward in a straight-line motion or move about in circular motion "doodling" patterns on a long roll of paper taped to the floor (Figure 4, right). Except for the DC motors and battery holders, which were purchased online from Amazon, all other materials were readily available. The online website Instructables provided a similar Doodlebot construction activity [10]. However, the Girl Makers Doodlebot workshop used electrical tape in lieu of a hot glue gun and purchased motors and battery holders with pre-existing attached wires, which obviated the need for using a side cutter and wire stripper. These substitutions precluded the chance for burns, cuts, and other minor injuries to the young makers. Prior to making the robot, the faculty asked the students to consider how a robot moves about, where the source of power comes from, and then discussed various energy conversions (i.e., electrical to mechanical energy, rotational energy to kinetic energy: moving robot forward) and the importance of closing the loop of an electric circuit. To illustrate the steps to build the robot, a brief presentation was given identifying the 
materials for the activity, showing the purpose of each components, and explaining how to attach the individual robot parts.

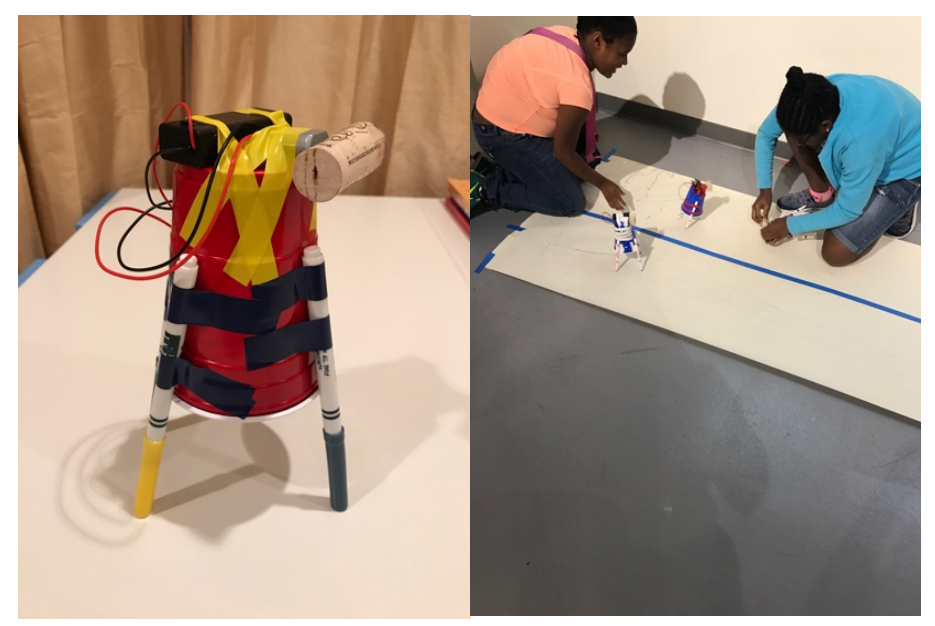

Figure 4. Doodlebot robot (left) and Girl Makers letting their robots doodle.

To help each girl feel ownership over her Doodlebot robot, the girls were also provided with additional materials and accessories that included stickers of googly eyes, red lips, and numbers to personalize the robots. A number of students towards the end of the session had named their robots and engaged the volunteers about careers in engineering and robotics.

\section{Coding with Arduino and Creating Art on A LED Panel}

The coding exercises introduce the Girl Makers to Arduino C programming while allowing them to express their creativity by creating their own graphical designs on $32 \times 32$ pixel RGB LED panels. The exercise is ideally intended for two or three students to a panel, to encourage discussion and collaboration while allowing all students to have a chance to write code. Students are first presented with an initial set of tutorial exercises. These exercises were originally created by the Department of Engineering Technology to host a small group of 10-15 Philadelphia high school students visiting the department for a day of coding and covered launching the Arduino IDE, writing a few commands to initialize the panel (this code is provided for them to copy), and learning to draw a few basic shapes on the screen (using intuitive commands like drawPixel(), drawCircle(), and drawLine(). The teaching instructions were not adapted for the middle school students due to time constraints. However, unlike the high school students who engaged in a challenge to create pre-determined art displays (i.e., American flag, curved rainbow, and gradient from blue to green across the screen) after learning the basic drawing commands, the middle school students were allowed to freely design LED artworks to express their creativity.

In the process of creating the various displays, students are also introduced to the concept of RGB colors - specifically, how combining various intensities of red, green, and blue light can produce the wide range of colors that we have come to expect from our electronic devices. This same 24-bit RRGGBB color scheme, or something similar, is used throughout the embedded 
industry. By learning which values produce which colors (for instance, deep orange might be $\mathrm{r}=255, \mathrm{~g}=64, \mathrm{~b}=0$ ), the students learned the modern technical language of emissive color. Colors on the RGB LED panel are specified in the same color space as websites, smartphone screen graphics, video games, and much more.

The Girl Makers participants expressed interest in the opportunity to design and create their own artwork such as the "Minion" art shown in Figure 6 (right).

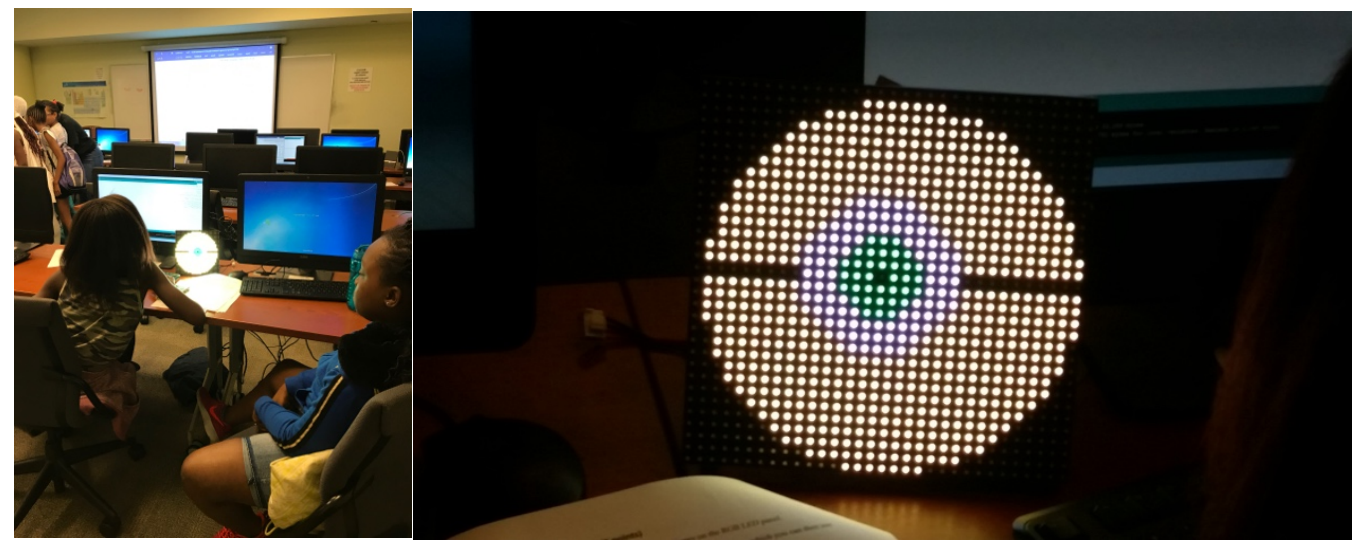

Figure 6. Some of the Girl Marker artists at work (left) creating the "Minion" on the RGB panel (right).

\section{Making Concrete Paperweights}

In this project, the Girl Makers were introduced to the fundamentals of one of the most ubiquitous materials in the built environment: concrete. The girls who participated in this activity were introduced to the use of concrete as a building material through a brief presentation and asked to identify places where they may find concrete on a daily basis. The goal was to alert them to the many applications of this basic construction material.

The exercise then progressed to a discussion of each component that makes up the composite material they all know as concrete. Students were introduced to sand, aggregate, cement and water, and the science and chemistry behind how these materials are combined in the correct proportions make concrete. Safety when handling the raw ingredients of concrete was also discussed to ensure the girls understood the importance of wearing the appropriate safety gear when mixing concrete.

After an overview of the basic concrete materials, the girls were each given a container to mix their own concrete and a sample mix design that indicated the correct amounts of each ingredient that should be added to the mix. The activity used the analogy of baking a cake to illustrate the way that the ingredients would be mixed to ensure a strong concrete. Once the concrete was mixed, the girls were able to choose a coloring agent to add to the concrete to change the color from grey to either red or blue. 
The next step was select their molds to make their paperweights. These molds were in the shape of hearts, flowers and butterflies. During this time, the volunteer faculty discussed with the girls how concrete is placed with formwork to create concrete structures and how it is important to place a releasing agent on the forms to ensure the concrete does not stick to the form. In this activity, the girls sprayed the molds with WD-40. Once the molds were prepared the girls placed the concrete into them, placed them in a plastic bag and were instructed to let the paperweights cure overnight before removing them from the molds.

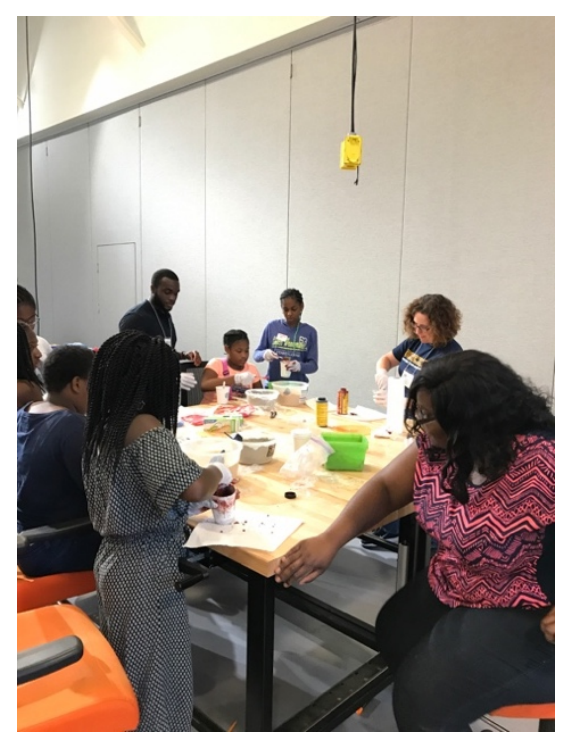

Figure 7. Girl Makers mixing concrete and making paperweights.

This activity was designed to be accessible to middle school-aged students and to teach them about the chemistry and fundamental ingredients of a common building material they come in contact with every day. The mixing of the concrete and making the paperweights allows them the hands-on experience of "building" with concrete on a small scale.

\section{Using CAD and CNC Laser Cutter to Design \& Fabricate a Dragon Keychain}

Today, K-12 schoolchildren learn how to use PowerPoint and Excel in their computer classes, and they still learn to draw and sculpt in art classes. But how much better would it be if they could choose a third option: a design and make class? When students are actively engaged in physical "making" projects, they are better able to discover their talents and develop the mental resources they need to think critically. But maintaining engagement can be a challenge, especially in middle school when both data and teacher experience point to a decline in student motivation [11,12]. Engagement is a well-known predictor of academic achievement. Students who stay engaged are better prepared for college and have greater confidence to pursue challenging majors like those in STEM fields [13]. 
The solution is to practice active learning. Active-learning practices — those that compel student participation - show a strong impact on performance for students of all backgrounds and achievement levels [14].

Through collaborative, hands-on projects, students could actively explore, respond to and engage with real-world challenges. When the challenge called for a physical solution, laser cutting and machining empowered students to navigate the entire design cycle from idea to finished product. One of the main goals of the design and fabrication of a keychain activity is to teach students how engineers solve problems and manage projects. This making activity, which had the students used computer-aided design (CAD) and a computer numerical control (CNC) laser cutter, engaged students to create the design, analyze and build the concept to be simulated. Laser cutting and making activities helped students apply design thinking to build excitement and momentum behind any classroom project $[15,16]$. Through inquiry and iteration, students learn as much by what goes wrong as what goes right, building their capacity for critical thinking and analysis, improving their judgment, and increasing their perseverance through applied learning.

Figure 8 below shows, from left to right, the progress of the design and fabrication activity as follows. A volunteer walks the student participants through an AutoCAD exercise (8a). Another volunteer demonstrates a CNC laser cutting process $(8 \mathrm{~b})$ and finally a volunteer helps students color their designs while informally discussing their experience in the activity (8c). A sample finished keychain which the student participants were able to take away as souvenirs of their efforts is shown in Figure 8d.

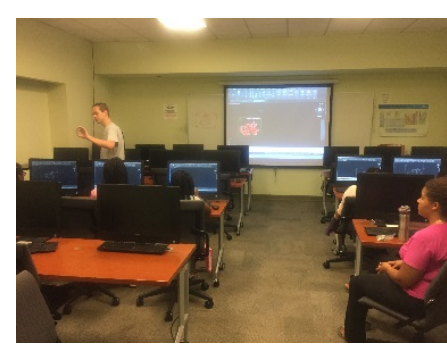

(a)



(b) (c)

Figure 8. (a) Drexel Dragon AutoCAD design explained by TA (Engineering Technology student, Ben Cohen), (b) Laser Cutting Process explained by Graduate TA (Prashant Yadav), (c) Students coloring Dragon keychain designs (left and middle), (d) Finished keychain

\section{Feedback Survey}

At the end of the Drexel STEM University for girls summer program, a feedback questionnaire was provided to the participating students to rate all the activities, using the score of " 1 " for least 
liked and " 5 " for most liked, and provide feedback to the organizers and volunteer instructors. The following Table 1 provides the summary of all activities and their associated rating scores. The table also provides the students' responses to whether the week's program increased their interests in STEM.

\begin{tabular}{|l|c|c|}
\hline \multicolumn{1}{|c|}{ Activity } & Activity Score & $\begin{array}{c}\text { Increase STEM } \\
\text { interest? }\end{array}$ \\
\hline Tissue Engineering & 3.36 & Agree \\
\hline Tragedy of Commons & 3.33 & Neither \\
\hline $\begin{array}{l}\text { Designing with the } \\
\text { Sun }\end{array}$ & 2.83 & Neither \\
\hline Pasta Bridge & 4.47 & Agree \\
\hline Game Theory & 3.75 & Agree \\
\hline $\begin{array}{l}\text { Making: Coding with } \\
\text { Arduino }\end{array}$ & 4.13 & Strongly Agree \\
\hline $\begin{array}{l}\text { Making: } \text { 3D Design \& } \\
\text { Printing }\end{array}$ & 4.42 & Strongly Agree \\
\hline $\begin{array}{l}\text { Making: Concrete } \\
\text { Paperweights }\end{array}$ & 4.40 & Agree \\
\hline Making: Doodlebots & 4.83 & Agree \\
\hline $\begin{array}{l}\text { Making: CAD \& CNC } \\
\text { Laser Cutting }\end{array}$ & 3.60 & Agree \\
\hline $\begin{array}{l}\text { Self-healing } \\
\text { infrastructure }\end{array}$ & 4.29 & Agree \\
\hline Water filtration & 3.85 & Neither \\
\hline Dry Ice Experiment & 5.00 & Neither \\
\hline Data Science & 2.00 & \\
\hline Material Behavior & 4.00 & \\
\hline
\end{tabular}

Table 1. Feedback Survey Results for All STEM Activities

Noting that not all 24 girls had participated in every activity, of the activities rated, the Doodlebot making activity received a score of 4.83 out of 5 , ranking as second best activity. The highest rated activity was a science experiment using dry ice. For the other Girl Makers activities-- 3D printing, concrete paperweights, Arduino coding, and CNC laser cutting, the scores were $4.42,4.40,4.13$, and 3.60 , respectively and the respective rankings for these activities were $4,5,7$, and 11 out of 17 total activities. The average score for all rated activities was 3.88 .

The participants were asked on a scale of "Strongly Disagree", "Disagree", "Neither", "Agree", and "Strongly Agree" if participation in the Drexel STEM University for girls had increased their interest in STEM. All the Girl Makers activities received either "Strongly Agree" or "Agree". 
The participants were asked to rate their overall experience with the Drexel STEM University for girls on a scale of "Poor", "Good", "Very Good", and "Excellent." All participants responded "Good" to "Excellent."

The questionnaire asked if the students had any prior experience similar to the activities offered in the STEM University. Among the Girl Makers responses, 8 had prior experience with programming and 5 had for 3D printing and building a robot. No students had any prior experience with concrete paperweights or CNC laser cutting.

The questionnaire had also asked the participants to comment on what were their favorite activities, least favorite activities, and what improvements they would like to see in future workshops. These responses were collected for all workshops offered, which include the 5 Girl Makers activities. Favorites ranged from listing specific activities such as 3D printing and dry ice to making friends, "learning to do new things," and "everything." Least favorites included "nothing" to sitting in silence to waking up early. On suggestions for improvement, two comments were "it was just right" while some wanted more building activities, more fun experiments, and more time to talk to professors.

The feedback questionnaire did provide a wealth of information for this first time offering of the Drexel STEM University for girls. Beyond exposing the girl participants to STEM, the average activity score of 3.88 out of 5 indicated that participants enjoyed the STEM activities that they were engaged in. As exposure and engagement were the main goals for the inaugural Girl Makers and Drexel STEM University, we felt that the activities were successful in achieving these goals. We are incorporating the feedback for our second joint effort of Girl Makers this coming summer 2018. In the second iteration of the programs, the intention is to add individual making activity surveys and an overall Girl Makers survey. Specifically, this is to identify within each making activity, what improvements could be made and collect ideas for other making activities that the participants would like to experience. Additionally, while the girls enjoyed the fun and creativity of programming the LED panel using Arduino, they expressed disappointment that unlike the other making activities, they could not take something home. Therefore, the creators of Girl Makers are identifying another activity that could potentially provide similar experiences but with a take-home item. Our major limitation is cost as both Girl Makers and the overall Drexel STEM University for girls are minimally funded by the College of Engineering, and organized and run by volunteers who incorporated re-usable items or low-cost items which were individually purchased by the instructors. At present, the Drexel STEM University for girls and Girl Makers are actively seeking support to purchase activity materials, pay for activity developments such as formulating a theme, and incorporate assessment for learning outcomes. Support would permit us to begin formally incorporating pre- and post-tests to gauge learning outcomes and assess the learning effectiveness of the activities, potentially extending beyond our first goals of STEM exposure and engagement.

\section{References}


[1] S. Rogers, S. Harris, I. Fidan, and D. McNeel, "Art2STEM: Building a STEM Workforce at the Middle School Level," ASEE Annual Conference and Exposition, Vancouver, BC, June 26-29, 2011.

[2] M. Bright, "The Importance of Early, Consistent Exposure to STEM Fields," Huffington Post, May 5, 2017. https://www.huffingtonpost.com/entry/the-importance-of-early-andconsistent-exposure-to us 5908e6b1e4b03b105b44bcdf

[3] S. Oberoi, "The Economic Impact of Early Exposure to STEM Education," Committee for Economic Development, June 21, 2016. https://www.ced.org/blog/entry/the-economicimpact-of-early-exposure-to-stem-education

[4] H. Mosatche, S. Matloff-Nieves, L. Kekelis, and E. Lawner, "Effective STEM Programs for Adolescent Girls: Three Approaches and Many Lessons Learned," Afterschool Matters, Spring 2013. PDF provided by National Girls Collaborative Project:

http://niost.org/images/pdf/afterschoolmatters/asm $2013 \quad 17$ spring/ASM 2013 spring 6. pdf

[5] A. Thomas, "Encouraging students in the STEM classroom through Making," Maker Education, edutopia, September 7, 2012. http://www.edutopia.org/

[6] L. Stamper, "What are MakerSpaces and how does it relate to STEM?," Pearson Communities, October 29, 2014. http://www.teachability.com/community/

[7] B. Terranova, L. Khuon, and A. Fontecchio "Makerspaces First: A First-year Engineering Program in an Academic Makerspace," $2^{\text {nd }}$ International Symposium on Academic Makerspaces, Cleveland, September 24-27, 2017.

[8] J. Linsey, "Understanding the Impact in University Makerspaces," in Proceedings of the

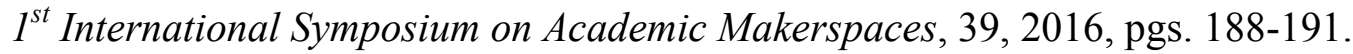

[9] TinkerCAD, https://www.tinkercad.com/

[10] “Let's Make a Doodlebot," MakeShop, Instructables, February 26, 2017, http://www.instructables.com/id/LETS-MAKE-a-DOODLEBOT/

[11] M. Prince, "Does Active Learning Work? a Review of the Research," Journal of Engineering Education, vol. 93, 2004.

[12] W. Birmingham, V. DiStasi, and G. Welton, "Learning style, student motivation, and active learning," ASEE Annual Conference and Exposition, Austin, TX, June 14-17, 2009.

[13] E. Froyd, White paper on promising practices in undergraduate stem education. Commissioned paper for the Evidence on Promising Practices in Undergraduate Science, Technology, Engineering, and Mathematics (STEM) Education Project, 2008

[14] D. W. Johnson, R. T. Johnson, and K. A. Smith, Active Learning: Cooperation in the College Classroom, ed, 1998.

[15] Gijbels, D., F. Dochy, P. Van Den Bossche, and M. Segers, 2005: Effects of problembased learning: A meta-analysis from the angle of assessment. Review of Educational Research, 75(1), 27-61.

[16] Hake, R. R., 1998: Interactive-engagement versus traditional methods. American Journal of Physics, 66, 64-74. 